\title{
Trends in CPAP adherence over twenty years of data collection: a flattened curve
}

Brian W. Rotenberg ${ }^{1}$, Dorian Murariu ${ }^{1}$ and Kenny P. Pang ${ }^{2^{*}}$

\begin{abstract}
Background: Obstructive sleep apnea (OSA) is a common disorder, and continuous airway positive pressure (CPAP) is considered to be the gold standard of therapy. CPAP however is known to have problems with adherence, with many patients eventually abandoning the device. The purpose of this paper is to assess secular trends in CPAP adherence over the long term to see if there have been meaningful improvements in adherence in light of the multiple interventions proposed to do so.

Methods: A comprehensive systematic literature review was conducted using the Medline-Ovid, Embase, and Pubmed databases, searching for data regarding CPAP adherence over a twenty year timeframe (1994-2015). Data was assessed for quality and then extracted. The main outcome measure was reported CPAP non-adherence. Secondary outcomes included changes in CPAP non-adherence when comparing short versus long-term, and changes in terms of behavioral counseling.

Results: Eighty-two papers met study inclusion/exclusion criteria. The overall CPAP non-adherence rate based on a 7-h/night sleep time that was reported in studies conducted over the twenty year time frame was $34.1 \%$. There was no significant improvement over the time frame. Behavioral intervention improved adherence rates by $\sim 1 \mathrm{~h}$ per night on average.

Conclusions: The rate of CPAP adherence remains persistently low over twenty years worth of reported data. No clinically significant improvement in CPAP adherence was seen even in recent years despite efforts toward behavioral intervention and patient coaching. This low rate of adherence is problematic, and calls into question the concept of CPAP as gold-standard of therapy for OSA.
\end{abstract}

Keywords: Obstructive sleep apnea, CPAP, Adherence, Uvuloplataopharyngoplasty

\section{Background}

Obstructive sleep apnea (OSA) is a common disorder affecting 3-9 \% of the general population and is well demonstrated to be a risk factor for resistant hypertension, fatal and non-fatal cardiovascular disease, neurological disease, and all-cause mortality [1]. OSA has predictable effects on decreasing economic outcomes, and is also a source of car accidents $[1,2]$. Since the pervasive health effects of untreated OSA are so well described, practice parameters published by the American Academy of Sleep Medicine (AASM) recommend that continuous positive airway pressure (CPAP) should be considered both first-line and gold-standard treatment

\footnotetext{
* Correspondence: drkpang@gmail.com

${ }^{2}$ Asia Sleep Centre, Paragon, 290, Orchard Road, Unit 18-04, Singapore

238859, Singapore

Full list of author information is available at the end of the article
}

for OSA; many prominent published studies make similar statements [2-5].

When used as prescribed, CPAP reduces daytime sleepiness, normalizes sleep architecture, and improves numerous OSA-specific health outcomes [6]. The sense of CPAP being considered gold standard of therapy has become so entrenched within health that many North American remunerating agencies, be they government insurance or private plans, as well as in the medicolegal world, have adopted the position that patients must undergo a trial of CPAP prior to being considered for any other more invasive intervention. However, the AASM parameters also recognized that a significant proportion of patients are unable to tolerate CPAP therapy, and frequently seek alternate treatment [2]. 
Despite numerous advances in machine dynamics including quieter pumps, softer masks, and improved portability, adherence to CPAP continues to be a problem frequently encountered in clinician's offices, with adherence rates generally ranging from 30 to $60 \%[7,8]$. There are many reasons for this problem including comfort, convenience, claustrophobia, and cost. [2] It is also understood that many patients who start on a path to non-adherence frequently remain non-adherent and eventually abandon the machine altogether, with consequent return of symptoms and OSA-specific adverse consequences. Finally, although "optimal" adherence rates in the literature range from 4 to $6 \mathrm{~h}$ per night, it is becoming increasingly recognized that data used to define "optimal" or even "sufficient" use also very much related the outcome measure being studied as well as patient self-perception of their own OSA severity. Until recently such adherence data were underemphasized in the CPAP literature, giving the medical community at large a somewhat unrealistic sense of the effectiveness of the device as a blanket treatment for all comers with OSA. Perhaps consequently CPAP continues to stand at the top of the treatment modality spectrum for OSA despite the problematic shortcomings described above.

The purpose of the current study was to investigate whether or not there has been a change in CPAP adherence trends over the long term. This information is important when counseling patients about the likelihood of treatment success when a CPAP prescription is given.

\section{Methods}

Our review was carried out in accordance with the preferred reporting items for systematic review and metaanalysis protocols (PRISMA-P) 2015 statement. A comprehensive systematic literature review was conducted using the Medline-Ovid, Embase, and Pubmed databases.

The primary search objective was to identify all papers reporting the results of clinical trials that used CPAP for the treatment of adults with OSA, and then to subsequently extract data on adherence if it was reported. The first step was a locate and review all of the studies listed for analysis in two major literature reviews, a Cochrane Collaboration review [9] and a second systematic literature review published by the National Institutes of Health Research (NIHR) [10] on the use of CPAP for the treatment of OSA. The second step was an extensive search of the PubMed/MedLine database, initiated using the following combined search terms (using both British and American spellings): "CPAP and obstructive sleep apnea" ( $n=3058)$. From this list, studies were identified that (a) did not replicate studies already found (b) were otherwise eligible for inclusion and (c) comprise primary data, i.e. not reviews or guidelines. The third and final step was a review of all reference lists and tables of other studies found within papers identified in the second step. A PhD level biostatistician performed all three of the initial search steps. EBM rankings were used to assess data quality.

Articles were considered for inclusion into the study by reviewing the titles and abstracts of all retrieved studies. The senior study authors BWR and KPP did this and results were compiled to ensure no studies were missed. The full text of selected studies were then analyzed to ensure that the following inclusion criteria were met: diagnosis of OSA, no confounding data for central sleep apnea, and the paper referred to CPAP for treatment of OSA. Subsequently we reviewed the studies to ensure adherence data was reported, and that if reported it was by machine audit as opposed to patient-self-report.

\section{Results}

A total of 82 papers were identified for analysis. These included trials comparing CPAP versus subtherapeutic (sham) CPAP [11-41], CPAP versus an oral placebo [40, 42-49], CPAP versus conservative or no therapy $[17,29,50-60]$, CPAP versus an oral appliance $[11,12,42,57,61-69]$, CPAP versus postural therapy [70-73], and CPAP alone assessing different means to modify adherence [15, 27, 37, 74-82]. The PRISMA chart summarizing the study flow is seen in Fig. 1.

\section{Overall CPAP adherence over the study duration}

Sixty-six studies published between 1994 and 2015, inclusive, were identified in the literature that had CPAP adherence data reported as hours of use per night and were either a randomized clinical trial or a longitudinal cohort study specifically addressing the issue of CPAP adherence in adult patients with OSA. Sample sizes in these studies ranged from 13 to 356 $($ mean $=65$, median $=37)$ subjects. The mean, nonweighted duration of nightly use was $4.6 \mathrm{~h}$, from which the percentage of non-use, relative to optimum use, was calculated by subtracting 4.6 from $7.0 \mathrm{~h}$, dividing this by $7.0 \mathrm{~h}$ and converting to a percentage; in this instance $34.1 \%$ (i.e. the non-adherence rate). The weighted mean for nightly CPAP use was calculated by multiplying the mean use for each individual study by the number of CPAP users in that study, adding the resulting values from all 66 studies, and then dividing by the total number of subjects on CPAP across all studies; this yielded a weighted mean nightly CPAP use and percentage of use of $4.46 \mathrm{~h} / \mathrm{n}$ and $36.3 \%$, respectively.

Figure 2 depicts both the weighted and non-weighted mean percentage of non-use for all studies within each 2-year block starting with 1996-97. To incorporate studies from 2014, the final block, 2012-14, consists of 3 years. Note the initial decline in non-adherence from 

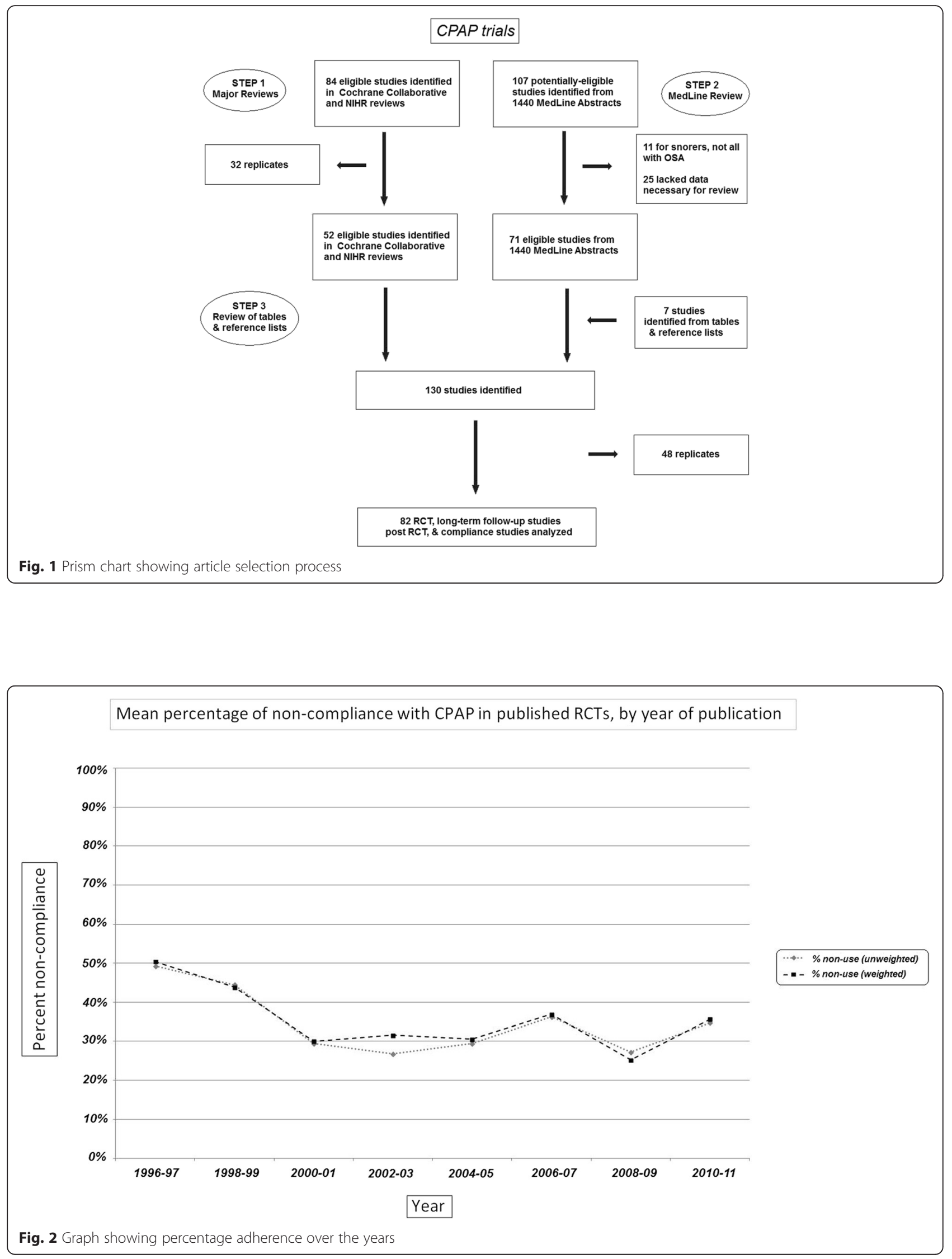
1996 to 97 through 2000-01, after which there is no decline. In fact, non-adherence for 2012-14 was higher than for any other time period from 2000 to 01 onwards, possibly reflecting improved data reporting. Note also the almost identical curves for non-weighted and weighted data.

\section{Adherence when comparing short-term versus long-term}

Eight studies were identified that had follow-up CPAP adherence assessments, including hours of CPAP use per night, 6 months or more since baseline, versus 64 studies with final assessments performed within the first 6 months. Again, both weighted and non-weighted means were calculated for mean nightly CPAP use and mean percentage of time CPAP was not used relative to the optimum $7.0 \mathrm{~h}$ per night. For the short-term studies, mean non-weighted and weighted mean values are 4.5 and $4.3 \mathrm{~h} /$ night, and 35.5 and $38.4 \%$ CPAP non-use, respectively. Corresponding values for the long-term studies are 4.6 and 4.6, and 34.2 and $33.6 \%$, indicating slightly superior adherence at follow-up assessments performed in patients on CPAP for 6 months or more. This is reflected in Fig. 3.

\section{Adherence rates in self-report versus machine- interrogation}

This analysis was restricted to studies in which measurements were made comparing both self-reported versus device-documented CPAP adherence values [79, 82]. In both studies, adherence was over-estimated by selfreport, as summarized in Table 1 . Note that for one of the studies, 'percentage of adherence' was the utilized measure of CPAP adherence, with adherence defined as four or more hours of use per night for $70 \%$ or more of nights. For the other study, mean hours use per night was presented. The non-weighted percentage of self-reported over-estimation (relative to machine-documented use) ranged from roughly 25 to $50 \%$, averaging $35.4 \%$.

\section{Adherence rates versus behavioral intervention}

Several RCTs were identified in which some behavioural intervention was evaluated in terms of its ability to impact CPAP adherence, measured as hours of CPAP use per night [84-90], Although increased use was documented in three studies [84-86], four RCT did not find support for the behavioural intervention [87-90]. Table 2 summarizes these results.

\section{Discussion}

CPAP is termed the gold standard for therapy of OSA and indeed when used as prescribed the health benefits are substantial. However this modality of treatment continues to be plagued by problems with adherence. The data identified in our review is the most up-to-date on the topic, and suggests that despite numerous interventions designed to improve adherence rates over the long term, secular trends do not show clinically impactful changes. The relatively poor adherence rates pre-2000 have not shown meaningful improvement over the ensuring 15 years, with overall rates stubbornly persistent at a high $30-40 \%$ non-adherence.

The further problem identified by our data is that of the reporting of CPAP in clinical trials. In our review of 82 CPAP trials, $10.7 \%$ of patients overall were unable to tolerate and thereby remain on CPAP over the duration of the trial in which they were participants, and the mean duration of nightly use was merely $4.7 \mathrm{~h}$. This

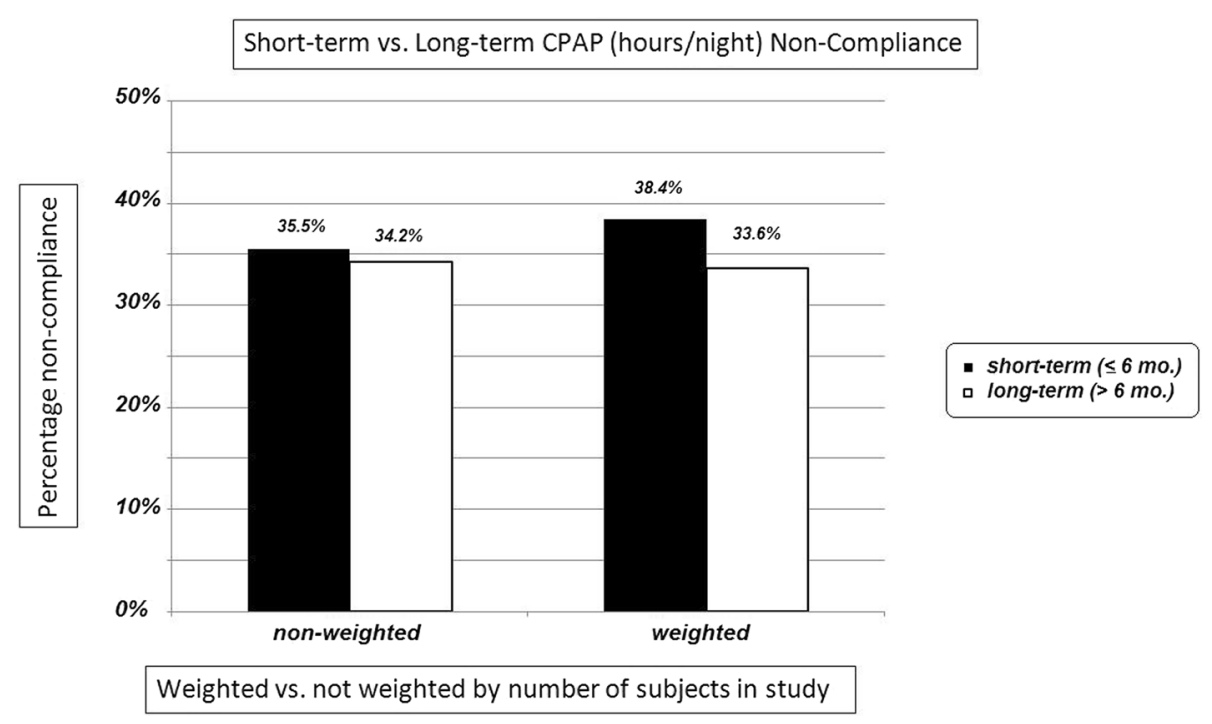

Fig. 3 Bar chart showing percentage adherence cpmaring weight and non-weightedsubjects in the study 
Table 1 Studies comparing self-reported vs. machine-documented CPAP compliance

\begin{tabular}{lllllll}
\hline 1st author (year) & Outcome & Subjects (N) & Self-report & CPAP device & Absolute difference & Percent difference \\
\hline Roecklein (2010) [79] & Hours per night at 3 months & 28 & 4.68 & 2.35 & 2.33 & $49.8 \%$ \\
Kribbs (1993) [83] & Hours per night over time & 35 & 4.9 & 3.7 & 1.2 & $24.5 \%$ \\
& & 311 & & & Mean $=$ & $35.4 \%$ \\
& & & & Weighted mean $=$ & $32.7 \%$ \\
\hline
\end{tabular}

means that the average patient in bed for $7 \mathrm{~h}$ across these 83 closely supervised clinical trials (i.e. under the most optimal of circumstances and the best chance for success at the therapy) was not using it an average of $32.9 \%$ of the time; extrapolating to 8 -h nights, this time off CPAP rises to $41.3 \%$. When the nights per week of CPAP non-use have been examined, the percentages range from 10 to $40 \%[12,44,56,61,70,74-76]$, with one in three out of 25 patients in a very brief, 2-week cross-over trial by Ferguson et al. only using CPAP one out of every three nights or less [62]. These are highly alarming percentages, given that several published RCT have documented that at least a minimum level of CPAP use is required to reap benefits from it and that this therapeutic threshold generally falls between 5 and $6 \mathrm{~h}$ nightly $[16,43,45,74,77]$. It is, therefore, reasonable to assume that there is a sizeable subset, possibly a majority, of patients on CPAP who either cease to use it altogether, or fail to use it enough hours per night and/ or nights per week to achieve clinically-significant benefits. This does call into question the validity of the results of some of these trials.

Prior to our study, Weaver et al. conducted the most recent prior review on CPAP as therapy for OSA in 2010, finding that there are many factors influencing CPAP adherence, both medical and non-medical (e.g. psychosocial), and that these need to be considered when both prescribing CPAP as well as designing effective interventions to improve adherence [7]. The authors wisely also pointed out that the cost-effectiveness of these interventions needs to be considered.

The most recent comprehensive literature review of CPAP adherence looks to be by Donovan et al. [91]. The authors investigated various outcomes including CPAP efficacy, behavioral interventions, and personalizing CPAP to patient need. The authors maintained that its main limitation is intolerability, which leads to low adherence. The authors call for more research on tailoring therapies to individual patients in order to enhance adherence.

The long-term effects of non-adherence bring to light the health related impact of untreated OSA. It is not sufficient to simply prescribe a CPAP machine and consider the patient to be treated. For example, BaHammam et al. [92] found that adherence to CPAP declined over a 10 -month period, such that only $33 \%$ of the OSA patients were considered to have "good adherence" by 10 months, even after receiving an educational intervention. Gagnadoux et al. [93] found that AHI scores and socioeconomic factors (employment and marital status) predicted mean CPAP adherence over several 6month follow-up assessments. Martinez-Garcia et al. [94] follow a sample of older adults who were prescribed CPAP for up to 10 years and found that severe OSA not treated with CPAP was associated with a higher risk of cardiovascular death, and CPAP use decreased this risk (albeit non significantly). Stuck et al. [95] conducted a retrospective chart review of 750 patients who were prescribed CPAP and follow-up over a 2-year period to quantify several sleep-related events such as hours of sleep without CPAP, and the number of respiratory events with and without CPAP. These authors concluded that CPAP has a limited effectiveness, even among patients who are most adherent to treatment.

Although a detailed discussion of the effectiveness of interventions to improve CPAP adherence is beyond the

Table 2 CPAP adherence versus behavioral intervention

\begin{tabular}{|c|c|c|c|c|c|c|c|}
\hline \multirow[t]{2}{*}{ 1st author (year) } & \multirow[t]{2}{*}{ Study design } & \multirow[t]{2}{*}{ Subjects (N) } & \multirow[t]{2}{*}{ Intervention } & \multirow[t]{2}{*}{ Follow-up } & \multicolumn{2}{|c|}{ CPAP use (h/n) } & \multirow[t]{2}{*}{ Significance } \\
\hline & & & & & Rx group & Controls & \\
\hline Lo Bue (2014) [99] & $\mathrm{RCT}$ & $20 / 20$ & "Reinforcing interventions" & 1 year & 4.3 & 3.8 & NS \\
\hline Lai (2014) [100] & $\mathrm{RCT}$ & $50 / 50$ & Motivational enhancement & 3 months & 4.4 & 2.4 & $p<0.001$ \\
\hline Deng (2013) [101] & $\mathrm{RCT}$ & $55 / 55$ & Stage-matched vs. standard care & 3 months & 5.65 & 5.26 & $p=0.006$ \\
\hline Olsen (2012) [102] & $\mathrm{RCT}$ & $50 / 50$ & 3 motivational interviews & 3 months & 4.63 & 3.16 & $p=0.005$ \\
\hline \multirow[t]{3}{*}{ Roecklein (2010) [79] } & $\mathrm{RCT}$ & $13 / 15$ & Personalized feedback & 3 months & 2.35 & 1.97 & NS \\
\hline & & & & Mean & 4.3 & 3.3 & $28.6 \% \uparrow$ \\
\hline & & & & Weighted mean & 4.7 & 3.5 & $32.0 \% \uparrow$ \\
\hline
\end{tabular}


scope of this current paper, several of the papers studied in our review did investigate these interventions [79, 92], including one review [96]. The strongest intervention, cognitive-behavioral, resulted in an increase of $1.44 \mathrm{~h}$ per night for participants in six studies. Both supportive and educational interventions were found to increase adherence to over 4 hours per night among study participants. Non-behavioral interventions for CPAP adherence, such as variants of CPAP, have also been investigated. A systematic review and meta-analysis found that patients preferred auto-CPAP over fixed pressure CPAP; however, there was no statistical difference in machine use [97]. Overall the authors did not find a difference in adherence between auto- and fixed-CPAP. Similarly, a more recent systematic review and meta-analysis found positive results associated with auto-CPAP over fixed-CPAP, including patient preference and enhanced adherence [98]. However, the latter did not found significant differences between the two variants in terms of AHI and ESS scores, leading the authors to question the clinical significance of their results.

As a systematic review, this study is limited to the quality of the included studies. Because it is a collection of findings from various other studies, it provides an overview of the direction of literature but is unable to show new findings. The authors recognize that in one study, CPAP was prescribed in patients with mild OSA, this might suggests that these patients who have no significant symptoms might not be compelled to use their CPAP device. It is also understandable that some patients may not sleep $7 \mathrm{~h}$ per night, as they are the working class group and may be too busy, and this might also affect the compliance percentage as the denominator is smaller. The older age group may have fragmented sleep patterns while the younger age group may not choose to wear their CPAP for social reasons. This study is also limited in the fact that only English language articles are considered, which may introduce a language bias. However, studies are published from a variety of centers internationally. Because this study is not a meta-analysis, study results have not been statistically combined for more powerful results. However, since adherence rates to CPAP are often measured differently, as are the defined outcome points for success, it is not feasible to directly compare papers in a statistically sound method.

\section{Conclusion}

This review represents the most up to date data on secular trends in CPAP adherence. The findings are sobering. Our data suggest that despite numerous changes to machine and mask dynamics as well as behavioral interventions, CPAP adherence remains a severe problem for management of patients with OSA - the concept of CPAP as gold standard for OSA therapy is no longer valid. This paper's data regarding a comprehensive assessment of CPAP adherence can be used when developing OSA treatment guidelines and when counseling patients about their OSA and the relative likelihood of treatment success for the various therapies at hand.

\section{Acknowledgements \\ Not applicable. \\ Funding \\ No funding.}

Availability of data and materials

Not applicable, data is already from other articles.

\section{Authors' contributions}

All authors involved in data collection and article writing. All authors read and approved the final manuscript.

\section{Authors' information}

Not applicable.

\section{Competing interests}

The authors declare that they have no competing interests.

Consent for publication

Not applicable.

Ethics approval and consent to participate

Not applicable

Financial disclosure

There are no financial interests to declare. This study was not funded by any granting or industry source.

\section{Author details}

${ }^{1}$ Department of Otolaryngology - Head and Neck Surgery, Western University, London, ON, Canada. ${ }^{2}$ Asia Sleep Centre, Paragon, 290, Orchard Road, Unit 18-04, Singapore 238859, Singapore.

Received: 14 June 2016 Accepted: 11 August 2016

Published online: 19 August 2016

\section{References}

1. Young T, Peppard PE, Gottlieb DJ. Epidemiology of obstructive sleep apnea: a population health perspective. Am J Respir Crit Care Med. 2002;165(9):1217-39.

2. Aurora RN, Casey KR, Kristo D, et al. Practice parameters for the surgical modifications of the upper airway for obstructive sleep apnea in adults. Sleep. 2010;33(10):1408-13.

3. Gay P, Weaver T, Loube D, Iber C. Evaluation of positive airway pressure treatment for sleep related breathing disorders in adults. Sleep. 2006;29(3):381-401

4. Morgenthaler TI, Aurora RN, Brown T, et al. Practice parameters for the use of autotitrating continuous positive airway pressure devices for titrating pressures and treating adult patients with obstructive sleep apnea syndrome: an update for 2007. An American Academy of Sleep Medicine report. Sleep. 2008;31(1):141-7.

5. Yaremchuk K, Tacia B, Peterson E, Roth T. Change in Epworth Sleepiness Scale after surgical treatment of obstructive sleep apnea. Laryngoscope. 2011;121(7):1590-3.

6. Alves C, Caminha JMPC, da Silva AM, Mendonça D. Compliance to continuous positive airway pressure therapy in a group of Portuguese patients with obstructive sleep apnea syndrome. Sleep Breath. 2012;16(2):555-62.

7. Weaver TE, Sawyer AM. Adherence to continuous positive airway pressure treatment for obstructive sleep apnoea: implications for future interventions. Indian J Med Res. 2010;131:245-58. 
8. Weaver TE, Grunstein RR. Adherence to continuous positive airway pressure therapy: the challenge to effective treatment. Proc Am Thorac Soc. 2008;5(2):173-8.

9. Giles TL, Lasserson TJ, Smith BJ, White J, Wright J, Cates CJ. Continuous positive airways pressure for obstructive sleep apnoea in adults: a cochrane collaboration review. Chichester: John Wiley \& Sons, Ltd; 1996.

10. McDaid C, Griffin S, Weatherly H, et al. Continuous positive airway pressure devices for the treatment of obstructive sleep apnoea-hypopnoea syndrome: a systematic review and economic analysis. Health Technol Assess. 2009;13(4):iii - iv, xi - xiv, 1-119, 143-274.

11. Aarab G, Lobbezoo F, Heymans MW, Hamburger HL, Naeije M. Long-term follow-up of a randomized controlled trial of oral appliance therapy in obstructive sleep apnea. Respiration. 2011;82(2):162-8.

12. Aarab G, Lobbezoo F, Hamburger HL, Naeije M. Oral appliance therapy versus nasal continuous positive airway pressure in obstructive sleep apnea: a randomized, placebo-controlled trial. Respiration. 2011;81(5):411-9.

13. Ancoli-Israel S, Palmer BW, Cooke JR, et al. Cognitive effects of treating obstructive sleep apnea in Alzheimer's disease: a randomized controlled study. J Am Geriatr Soc. 2008:56(11):2076-81.

14. Arias MA, García-Río F, Alonso-Fernández A, Martínez I, Villamor J. Pulmonary hypertension in obstructive sleep apnoea: effects of continuous positive airway pressure: a randomized, controlled cross-over study. Eur Heart J. 2006;27(9):1106-13.

15. Bakker J, Campbell A, Neill A. Randomized controlled trial comparing flexible and continuous positive airway pressure delivery: effects on compliance, objective and subjective sleepiness and vigilance. Sleep. 2010;33(4):523-9.

16. Barbé F, Mayoralas LR, Duran J, et al. Treatment with continuous positive airway pressure is not effective in patients with sleep apnea but no daytime sleepiness. a randomized, controlled trial. Ann Intern Med. 2001;134(11):1015-23.

17. Barbé F, Durán-Cantolla J, Capote F, et al. Long-term effect of continuous positive airway pressure in hypertensive patients with sleep apnea. Am J Respir Crit Care Med. 2010;181(7):718-26.

18. Becker HF, Jerrentrup A, Ploch $\mathrm{T}$, et al. Effect of nasal continuous positive airway pressure treatment on blood pressure in patients with obstructive sleep apnea. Circulation. 2003;107(1):68-73.

19. Campos-Rodriguez F, Grilo-Reina A, Perez-Ronchel J, et al. Effect of continuous positive airway pressure on ambulatory BP in patients with sleep apnea and hypertension: a placebo-controlled trial. Chest. 2006;129(6):1459-67.

20. Coughlin SR, Mawdsley L, Mugarza JA, Wilding JPH, Calverley PMA. Cardiovascular and metabolic effects of CPAP in obese males with OSA. Eur Respir J. 2007;29(4):720-7.

21. Cross MD, Mills NL, Al-Abri M, et al. Continuous positive airway pressure improves vascular function in obstructive sleep apnoea/hypopnoea syndrome: a randomised controlled trial. Thorax. 2008;63(7):578-83.

22. Dimsdale JE, Loredo JS, Profant J. Effect of continuous positive airway pressure on blood pressure: a placebo trial. Hypertension. 2000;35(1):144-7.

23. Durán-Cantolla J, Aizpuru F, Montserrat JM, et al. Continuous positive airway pressure as treatment for systemic hypertension in people with obstructive sleep apnoea: randomised controlled trial. BMJ. 2010;341:c5991.

24. Egea CJ, Aizpuru F, Pinto JA, et al. Cardiac function after CPAP therapy in patients with chronic heart failure and sleep apnea: a multicenter study. Sleep Med. 2008;9(6):660-6.

25. Henke KG, Grady JJ, Kuna ST. Effect of nasal continuous positive airway pressure on neuropsychological function in sleep apnea-hypopnea syndrome. A randomized, placebo-controlled trial. Am J Respir Crit Care Med. 2001;163(4):911-7.

26. Hui DS, To KW, Ko FW, et al. Nasal CPAP reduces systemic blood pressure in patients with obstructive sleep apnoea and mild sleepiness. Thorax. 2006;61(12):1083-90.

27. Jenkinson C, Davies RJ, Mullins R, Stradling JR. Long-term benefits in selfreported health status of nasal continuous positive airway pressure therapy for obstructive sleep apnoea. QJM. 2001;94(2):95-9.

28. Jenkinson C, Davies RJ, Mullins R, Stradling JR. Comparison of therapeutic and subtherapeutic nasal continuous positive airway pressure for obstructive sleep apnoea: a randomised prospective parallel trial. Lancet (London, England). 1999;353(9170):2100-5.

29. Lojander J, Maasilta P, Partinen M, Brander PE, Salmi T, Lehtonen H. NasalCPAP, surgery, and conservative management for treatment of obstructive sleep apnea syndrome. Chest. 1996;110(1):114-9.
30. Loredo JS, Ancoli-Israel S, Kim E-J, Lim WJ, Dimsdale JE. Effect of continuous positive airway pressure versus supplemental oxygen on sleep quality in obstructive sleep apnea: a placebo-CPAP-controlled study. Sleep. 2006:29(4):564-71

31. Marshall NS, Neill AM, Campbell AJ, Sheppard DS. Randomised controlled crossover trial of humidified continuous positive airway pressure in mild obstructive sleep apnoea. Thorax. 2005;60(5):427-32.

32. Marshall NS, Neill AM, Campbell AJ. Randomised trial of compliance with flexible (C-Flex) and standard continuous positive airway pressure for severe obstructive sleep apnea. Sleep Breath. 2008;12(4):393-6.

33. Montserrat JM, Ferrer M, Hernandez L, et al. Effectiveness of CPAP treatment in daytime function in sleep apnea syndrome: a randomized controlled study with an optimized placebo. Am J Respir Crit Care Med. 2001;164(4):608-13. doi:10.1164/ajrccm.164.4.2006034.

34. Norman D, Loredo JS, Nelesen RA, et al. Effects of continuous positive airway pressure versus supplemental oxygen on 24-hour ambulatory blood pressure. Hypertension. 2006:47(5):840-5.

35. Pepperell JCT, Ramdassingh-Dow S, Crosthwaite N, et al. Ambulatory blood pressure after therapeutic and subtherapeutic nasal continuous positive airway pressure for obstructive sleep apnoea: a randomised parallel trial. Lancet (London, England). 2002;359(9302):204-10.

36. Robinson GV, Smith DM, Langford BA, Davies RJO, Stradling JR. Continuous positive airway pressure does not reduce blood pressure in nonsleepy hypertensive OSA patients. Eur Respir J. 2006;27(6):1229-35.

37. Sharma SK, Agrawal S, Damodaran D, et al. CPAP for the metabolic syndrome in patients with obstructive sleep apnea. N Engl J Med. 2011;365(24):2277-86

38. Siccoli MM, Pepperell JCT, Kohler M, Craig SE, Davies RJO, Stradling JR. Effects of continuous positive airway pressure on quality of life in patients with moderate to severe obstructive sleep apnea: data from a randomized controlled trial. Sleep. 2008;31(11):1551-8

39. West SD, Nicoll DJ, Wallace TM, Matthews DR, Stradling JR. Effect of CPAP on insulin resistance and $\mathrm{HbA1c}$ in men with obstructive sleep apnoea and type 2 diabetes. Thorax. 2007;62(11):969-74.

40. Engleman HM, Martin SE, Deary IJ, Douglas NJ. Effect of continuous positive airway pressure treatment on daytime function in sleep apnoea/hypopnoea syndrome. Lancet (London, England). 1994;343(8897):572-5.

41. Spicuzza L, Bernardi L, Balsamo R, Ciancio N, Polosa R, Di Maria G. Effect of treatment with nasal continuous positive airway pressure on ventilatory response to hypoxia and hypercapnia in patients with sleep apnea syndrome. Chest. 2006;130(3):774-9.

42. Barnes M, McEvoy RD, Banks S, et al. Efficacy of positive airway pressure and oral appliance in mild to moderate obstructive sleep apnea. Am J Respir Crit Care Med. 2004;170(6):656-64.

43. Engleman HM, Gough K, Martin SE, Kingshott RN, Padfield PL, Douglas NJ. Ambulatory blood pressure on and off continuous positive airway pressure therapy for the sleep apnea/hypopnea syndrome: effects in \&quot;nondippers\&quot. Sleep. 1996;19(5):378-81.

44. Barnes M, Houston D, Worsnop CJ, et al. A randomized controlled trial of continuous positive airway pressure in mild obstructive sleep apnea. Am J Respir Crit Care Med. 2002;165(6):773-80.

45. Engleman HM, Kingshott RN, Wraith PK, Mackay TW, Deary IJ, Douglas NJ. Randomized placebo-controlled crossover trial of continuous positive airway pressure for mild sleep Apnea/Hypopnea syndrome. Am J Respir Crit Care Med. 1999;159(2):461-7.

46. Engleman HM, Martin SE, Kingshott RN, Mackay TW, Deary IJ, Douglas NJ. Randomised placebo controlled trial of daytime function after continuous positive airway pressure (CPAP) therapy for the sleep apnoea/hypopnoea syndrome. Thorax. 1998;53(5):341-5.

47. Faccenda JF, Mackay TW, Boon NA, Douglas NJ. Randomized placebocontrolled trial of continuous positive airway pressure on blood pressure in the sleep apnea-hypopnea syndrome. Am J Respir Crit Care Med. 2001;163(2):344-8. doi:10.1164/ajrccm.163.2.2005037.

48. McArdle N, Douglas NJ. Effect of continuous positive airway pressure on sleep architecture in the sleep apnea-hypopnea syndrome: a randomized controlled trial. Am J Respir Crit Care Med. 2001;164(8 Pt 1):1459-63. doi:10.1164/ajrccm.164.8.2008146.

49. McArdle N, Kingshott R, Engleman HM, Mackay TW, Douglas NJ. Partners of patients with sleep apnoea/hypopnoea syndrome: effect of CPAP treatment on sleep quality and quality of life. Thorax. 2001;56(7):513-8 
50. Ballester E, Badia JR, Hernández L, et al. Evidence of the effectiveness of continuous positive airway pressure in the treatment of sleep apnea/hypopnea syndrome. Am J Respir Crit Care Med. 1999;159(2):495-501.

51. Barbé F, Durán-Cantolla J, Sánchez-de-la-Torre M, et al. Effect of continuous positive airway pressure on the incidence of hypertension and cardiovascular events in nonsleepy patients with obstructive sleep apnea: a randomized controlled trial. JAMA. 2012;307(20):2161-8.

52. Chakravorty I, Cayton RM, Szczepura A. Health utilities in evaluating intervention in the sleep apnoea/hypopnoea syndrome. Eur Respir J. 2002;20(5):1233-8.

53. Drager LF, Bortolotto LA, Figueiredo AC, Krieger EM, Lorenzi GF. Effects of continuous positive airway pressure on early signs of atherosclerosis in obstructive sleep apnea. Am J Respir Crit Care Med. 2007:176(7):706-12.

54. Drager LF, Pedrosa RP, Diniz PM, et al. The effects of continuous positive airway pressure on prehypertension and masked hypertension in men with severe obstructive sleep apnea. Hypertension. 2011;57(3):549-55.

55. Hsu C-Y, Vennelle M, Li H-Y, Engleman HM, Dennis MS, Douglas NJ. Sleep-disordered breathing after stroke: a randomised controlled trial of continuous positive airway pressure. J Neurol Neurosurg Psychiatry. 2006;77(10):1143-9.

56. Kaneko Y, Floras JS, Usui K, et al. Cardiovascular effects of continuous positive airway pressure in patients with heart failure and obstructive sleep apnea. N Engl J Med. 2003;348(13):1233-41.

57. Lam B, Sam K, Mok WYW, et al. Randomised study of three non-surgical treatments in mild to moderate obstructive sleep apnoea. Thorax. 2007;62(4):354-9.

58. Mansfield DR, Gollogly NC, Kaye DM, Richardson M, Bergin P, Naughton MT. Controlled trial of continuous positive airway pressure in obstructive sleep apnea and heart failure. Am J Respir Crit Care Med. 2004;169(3):361-6.

59. Monasterio C, Vidal S, Duran J, et al. Effectiveness of continuous positive airway pressure in mild sleep apnea-hypopnea syndrome. Am J Respir Crit Care Med. 2001;164(6):939-43.

60. Redline S, Adams N, Strauss ME, Roebuck T, Winters M, Rosenberg C. Improvement of mild sleep-disordered breathing with CPAP compared with conservative therapy. Am J Respir Crit Care Med. 1998;157(3 Pt 1):858-65. doi:10.1164/ajrccm.157.3.9709042.

61. Engleman HM, McDonald JP, Graham D, et al. Randomized crossover trial of two treatments for sleep apnea/hypopnea syndrome: continuous positive airway pressure and mandibular repositioning splint. Am J Respir Crit Care Med. 2002;166(6):855-9. doi:10.1164/rccm.2109023.

62. Ferguson KA, Ono T, Lowe AA, Keenan SP, Fleetham JA. A randomized crossover study of an oral appliance vs nasal-continuous positive airway pressure in the treatment of mild-moderate obstructive sleep apnea. Chest. 1996;109(5):1269-75

63. Ferguson KA, Ono T, Lowe AA, Al-Majed S, Love LL, Fleetham JA. A shortterm controlled trial of an adjustable oral appliance for the treatment of mild to moderate obstructive sleep apnoea. Thorax. 1997:52(4):362-8.

64. Gagnadoux F, Fleury B, Vielle B, et al. Titrated mandibular advancement versus positive airway pressure for sleep apnoea. Eur Respir J. 2009;34(4):914-20

65. Hoekema A, Stegenga B, Wijkstra PJ, van der Hoeven JH, Meinesz AF, de Bont LGM. Obstructive sleep apnea therapy. J Dent Res. 2008;87(9):882-7.

66. Randerath WJ, Heise M, Hinz R, Ruehle K-H. An individually adjustable oral appliance vs continuous positive airway pressure in mild-to-moderate obstructive sleep apnea syndrome. Chest. 2002;122(2):569-75.

67. Tan YK, L'Estrange PR, Luo YM, et al. Mandibular advancement splints and continuous positive airway pressure in patients with obstructive sleep apnoea: a randomized cross-over trial. Eur J Orthod. 2002;24(3):239-49.

68. Trzepizur W, Gagnadoux F, Abraham P, et al. Microvascular endothelial function in obstructive sleep apnea: Impact of continuous positive airway pressure and mandibular advancement. Sleep Med. 2009;10(7): 746-52.

69. Doff MHJ, Hoekema A, Wijkstra PJ, et al. Oral appliance versus continuous positive airway pressure in obstructive sleep apnea syndrome: a 2-year follow-up. Sleep. 2013;36(9):1289-96.

70. Skinner MA, Kingshott RN, Jones DR, Taylor DR. Lack of efficacy for a cervicomandibular support collar in the management of obstructive sleep apnea. Chest. 2004;125(1):118-26.
71. Skinner MA, Kingshott RN, Jones DR, Homan SDR, Taylor DR. Elevated posture for the management of obstructive sleep apnea. Sleep Breath. 2004;8(4):193-200

72. Permut I, Diaz-Abad M, Chatila W, et al. Comparison of positional therapy to CPAP in patients with positional obstructive sleep apnea. J Clin Sleep Med. 2010;6(3):238-43.

73. Jokic R, Klimaszewski A, Crossley M, Sridhar G, Fitzpatrick MF. Positional treatment vs continuous positive airway pressure in patients with positional obstructive sleep apnea syndrome. Chest. 1999;115(3):771-81.

74. Ballard RD, Gay PC, Strollo PJ. Interventions to improve compliance in sleep apnea patients previously non-compliant with continuous positive airway pressure. J Clin Sleep Med. 2007;3(7):706-12.

75. Engleman HM, Martin SE, Douglas NJ. Compliance with CPAP therapy in patients with the sleep apnoea/hypopnoea syndrome. Thorax. 1994;49(3):263-6.

76. Kohler M, Stoewhas A-C, Ayers L, et al. Effects of continuous positive airway pressure therapy withdrawal in patients with obstructive sleep apnea: a randomized controlled trial. Am J Respir Crit Care Med. 2011;184(10):1192-9.

77. Kryger MH, Berry RB, Massie CA. Long-term use of a nasal expiratory positive airway pressure (EPAP) device as a treatment for obstructive sleep apnea (OSA). J Clin Sleep Med. 2011;7(5):449-453B.

78. Kushida CA, Berry RB, Blau A, et al. Positive airway pressure initiation: a randomized controlled trial to assess the impact of therapy mode and titration process on efficacy, adherence, and outcomes. Sleep. 2011;34(8):1083-92

79. Roecklein KA, Schumacher JA, Gabriele JM, Fagan C, Baran AS, Richert AC Personalized feedback to improve CPAP adherence in obstructive sleep apnea. Behav Sleep Med. 2010;8(2):105-12.

80. Ruhle K-H, Franke K-J, Domanski U, Nilius G. Quality of life, compliance, sleep and nasopharyngeal side effects during CPAP therapy with and without controlled heated humidification. Sleep Breath. 2011;15(3):479-85.

81. Ryan S, Doherty LS, Nolan GM, McNicholas WT. Effects of heated humidification and topical steroids on compliance, nasal symptoms, and quality of life in patients with obstructive sleep apnea syndrome using nasal continuous positive airway pressure. J Clin Sleep Med. 2009:5(5):422-7.

82. To KW, Chan WC, Choo KL, Lam WK, Wong KK, Hui DS. A randomized crossover study of auto-continuous positive airway pressure versus fixedcontinuous positive airway pressure in patients with obstructive sleep apnoea. Respirology. 2008;13(1):79-86.

83. Kribbs NB, Pack Al, Kline LR, et al. Objective measurement of patterns of nasal CPAP use by patients with obstructive sleep apnea. Am Rev Respi Dis. 1993;147(4):887-95.

84. Aloia MS, Ph D, Dio L Di, et al. Improving Compliance with Nasal CPAP and Vigilance in Older Adults with OSAHS. Sleep Breath. 2001;5(1):13-22.

85. Richards D, Bartlett DJ, Wong K, Malouff J, Grunstein RR. Increased adherence to CPAP with a group cognitive behavioral treatment intervention: a randomized trial. Sleep. 2007;30(5):635-40. doi:10.1037/ 0278-6133.23.2.207.

86. Demolles DA, Sparrow D, Gottlieb DJ, et al. A Pilot Trial of a Telecommunications System in Sleep Apnea Management. 2016;42(8):764-769. doi:10.1097/01. mlr.0000132353.99209.fe

87. Baron KG, Smith TW, Berg CA, Czajkowski LA, Gunn H, Jones CR. Spousal involvement in CPAP adherence among patients with obstructive sleep apnea. 2011:525-534. doi:10.1007/s11325-010-0374-z.

88. Wiese HJ, Boethel C, Phillips B, Wilson JF, Peters J, Viggiano T. CPAP compliance: Video education may help! Sleep Med. 2005;6(2):171-4. doi:10.1016/j.sleep.2004.08.006

89. Bartlett D, Wong K, Richards D, et al. Increasing adherence to obstructive sleep apnea treatment with a group social cognitive therapy treatment intervention: a randomized trial. Sleep. 2013:36:1647-54. doi:10.5665/sleep.3118.

90. Nadeem R, Rishi M a, Srinivasan L, Copur AS, Naseem J. Effect of Visualization of Raw Graphic Polysomnography Data by Sleep Apnea Patients on Compliance With CPAP Therapy. Respir Care. 2012:607-613. doi:10.4187/respcare.01539.

91. Donovan LM, Boeder S, Malhotra A, Patel SR. New developments in the use of positive airway pressure for obstructive sleep apnea. J Thorac Dis. 2015;7(8):1323-42. 
92. BaHammam AS, Alassiri SS, Al-Adab AH, et al. Long-term compliance with continuous positive airway pressure in Saudi patients with obstructive sleep apnea. A prospective cohort study. Saudi Med J. 2015; 36(8):911-9.

93. Gagnadoux F, Le Vaillant M, Goupil F, et al. Influence of marital status and employment status on long-term adherence with continuous positive airway pressure in sleep apnea patients. PLoS One. 2011;6(8):e22503.

94. Martínez-García M-A, Campos-Rodríguez F, Catalán-Serra P, et al Cardiovascular mortality in obstructive sleep apnea in the elderly: role of long-term continuous positive airway pressure treatment: a prospective observational study. Am J Respir Crit Care Med. 2012;186(9):909-16. doi:10.1164/rccm.201203-04480C.

95. Stuck BA, Leitzbach S, Maurer JT. Effects of continuous positive airway pressure on apnea-hypopnea index in obstructive sleep apnea based on long-term compliance. Sleep Breath. 2012;16(2):467-71.

96. Wozniak DR, Lasserson TJ, Smith I. Educational, supportive and behavioural interventions to improve usage of continuous positive airway pressure machines in adults with obstructive sleep apnoea. Cochrane Database Syst Rev. 2014;1:CD007736.

97. Smith I, Lasserson TJ. Pressure modification for improving usage of continuous positive airway pressure machines in adults with obstructive sleep apnoea. Cochrane Database Syst Rev. 2009;4:CD003531.

98. Xu T, Li T, Wei D, et al. Effect of automatic versus fixed continuous positive airway pressure for the treatment of obstructive sleep apnea: an up-to-date meta-analysis. Sleep Breath. 2012;16(4):1017-26.

99. Lo BA, Salvaggio A, Isidoro SI, Romano S, Marrone O, Insalaco G. Usefulness of reinforcing interventions on continuous positive airway pressure compliance. BMC Pulm Med. 2014;14:78.

100. Lai AY, Fong DY, Lam JC, Weaver TE, Ip MS. The efficacy of a brief motivational enhancement education program on CPAP adherence in OSA: a randomized controlled trial. Chest. 2014;146(3):600-10.

101. Deng T, Wang Y, Sun M, Chen B. Stage-matched intervention for adherence to CPAP in patients with obstructive sleep apnea: a randomized controlled trial. Sleep Breath. 2013;17(2):791-801.

102. Olsen S, Smith SS, Oei TP, Douglas J. Motivational interviewing (MINT) improves continuous positive airway pressure (CPAP) acceptance and adherence: a randomized controlled trial. J Consult Clin Psychol. 2012;80(1): $151-63$

\section{Submit your next manuscript to BioMed Central and we will help you at every step:}

- We accept pre-submission inquiries

- Our selector tool helps you to find the most relevant journal

- We provide round the clock customer support

- Convenient online submission

- Thorough peer review

- Inclusion in PubMed and all major indexing services

- Maximum visibility for your research

Submit your manuscript at www.biomedcentral.com/submit 